\title{
An Appropriate Wind Model for The Reliability Assessment of Incorporated Wind Power in Power Generation System
}

\author{
Abror Kurbanov, Mansur Khasanov ", Anvar Suyarov, Urinboy Jalilov, Bakhodir \\ Narimonov, and Alisher Boliev \\ Jizzakh Polytechnic Institute, Jizzakh, Uzbekistan
}

\begin{abstract}
The use of renewable energy sources (RES) by many power grids companies around the world has increased significantly in recent years. The trend towards the use of RES is mainly due to ecological problems and rising fuel prices related to conventional power generation. Wind power is an approved source for power generation among renewable sources that makes a positive contribution to the global, social and economic environment. Today, wind turbine generator (WTG) is a mature, abundant, and eco-friendly power generation technology, and much of the electricity demand is supplied by wind. However, the uncertain nature of wind speed poses a variety of challenges for the planning and operation of power systems. One of the problems in increasing wind power can be seen in terms of assessment of power system reliability. This paper presents a reliability assessment model of power generation systems (PGS), including WTG, by using an analytical method. The presented model in this paper applied to the Roy Billinton Test System (RBTS). The methodology and results presented in this paper are intended to provide useful information to planners or developers seeking to assess the reliability of PGSs, including WTG.
\end{abstract}

\section{Introduction}

The use of RES is growing significantly in many countries around the world. Government support and policy are the most important impetus for the development of the RES industry [1]. However, the unpredictability and variability of RES is a major obstacle to its development, causing several problems for power systems. Reliability, stability analysis, power system safety, and frequency regulation are key technical issues that affect when RES is integrated into PGS [2-4]. The growth of power grids with specific properties of wind power can add a lot of uncertainty to the reliability of the system and affect its ability to meet its electricity demand. It is vital to understand the contribution of WTG to the reliability of power systems and to assess their real ability to meet demand.

Assessment of the reliability of power systems in the being of WTGs is a major challenge. Because the characteristics of WTGs are different from conventional power generators, different methods need to be used to model them and evaluate their reliability

* Corresponding author: hasanov6654525@mail.ru 
contribution. In recent years, several probabilistic and analytical approaches have been developed to study the reliability of WTGs and calculate their reliability advantages [5-9]. Time series and negative load [5], the multi-state unit [6-8], and theprobabilistic distribution model of WT [9] are have been used recently. The first group uses chronological methods to assess reliability. These techniques can maintain the correlation between wind power and demand. Although, their main drawback is the wide evaluation time, especially in composite power systems. On the other hand, multi-stage and probability models [6-9] are fast but may not maintain the correlation between chronological features and data sets. However, some researchers have provided methods to maintain the link between wind power generation and load demand data [10-14]. These approaches still face challenges in modeling systems with a large number of RES. For example, wind power plants and demand data are modeled as three-dimensional clusters to maintain the interdependence between them [12]. Although, by increasing the number of wind power stations, the size of the matrix increases, and the calculations become more complicated. Furthermore, some methods, such as the non-iterative approach proposed in [14], are applied only at the generation level and do not address reliability assessments at the composite power system level.

This paper describes the analytical method for constructing a wind power station reliability model taking into account power variability and mechanical forced outage rate (FOR) of WTG. Theresulting model resembles the power state of a multi-state generating unit, expressed capacity outage probability table (COPT). This has the advantage that the entire wind power station can now be viewed as a single equivalent generating unit that can be incorporated into conventional probabilistic planning approaches without further considering the correlation between turbines within the station.

The rest of this paper is organized as follows: Section II presents the wind power generation model, Section III describes the load model, the simulation results are presented in section IV. In Section V conclusion of this work is presented.

\section{Materials and Methods}

\subsection{Wind power generation model of WTG}

Power generation using WTG is highly dependent on meteorological conditions. The power generation model of WTG will be divided into the following parts [15]:

\subsubsection{Wind speed modeling}

In this paper, the Markov chain process (MCP) has been used to predict wind speed. The process has been chosen concerning the stochastic nature of the wind speed, taking into account the probability of transition between wind speed conditions and the probability of occurrence[16]. The MCP is a stochastic approach that can now assess the probability of a system state from its previous state. When using the MCP in wind speed forecasting, it is first necessary to have historically collected wind speed. In this study, two years of hourly collected historical data used for forecasting. The data were collected from the Jizzakh region in Uzbekistan.

To generate new wind speed from the historical measured data by using MCP, the key steps are as follows:

1. Collect historical data of wind speed and classified these wind speed into $s$ numbers of states based on the amplitude of the wind speed.

2. After classifying the state, the probability of transition $p_{l m} 1$ state to another to 
another $m$ state at time $t$ to $(t+1)$ can be expressed as follows:

$$
p_{l m}=\frac{n_{l m}}{\sum n_{l m}} ; \quad l, m=1,2, \ldots, s ; \quad l \neq m
$$

where $n_{l m}$ is transition number from state $l$ to $m$

Transition Probability Matrix (TPM) of $\mathrm{s} \times \mathrm{s}$ is structured with the following $p_{l m}$ as follows:

$$
P=\left(p_{l m}\right)=\left(\begin{array}{cccc}
p_{11} & p_{12} & \cdots & p_{1 s} \\
p_{21} & p_{22} & \cdots & p_{2 s} \\
\cdots & \ldots & \cdots & \cdots \\
p_{s 1} & p_{s 2} & & p_{s s}
\end{array}\right)
$$

3. The TPM converted to a Cumulative Probability Matrix (CPM)

If there is a probability of transition in the $l t h$ row at the $k t h$ state is $P_{l k}$, then $P_{l k}$ will be cumulative probability and formulated as follows:

$$
P_{l k}=\sum_{m=1}^{k} p_{l m} ; \quad l, k=1,2, \ldots, s
$$

4. Create random $N$ numbers from 0 to 1

5. Randomly select the initial state and marked as $l$

6. If the created random value of $N$ is equal

7. If the $N$ value is less or equal to the element $l$ th row of CPM $\left(N \leq p_{i 1}\right)$, then 1 will be the next state. If $N$ is bigger than the $1^{\text {st }}$ element in the lth row of CPM and smaller than or equal to the sum of the first two elements for the same row, the next state will be 2 .

8. The transition from $l$ state to new $m$ state of CPM can be transmuted to wind speed $v_{s}$ as follows:

$$
v_{s}=v_{m-1}+N_{l}\left(v_{m}-v_{m-1}\right)
$$

where, $v_{m}$ and $v_{m-1}$ are upper and lower limits of wind speed, $N_{l}$ is a random number.

Take into consideration the current state as the initial state, and by repeating steps (7) and (8) for every random number, wind speed of any length can be generated. 


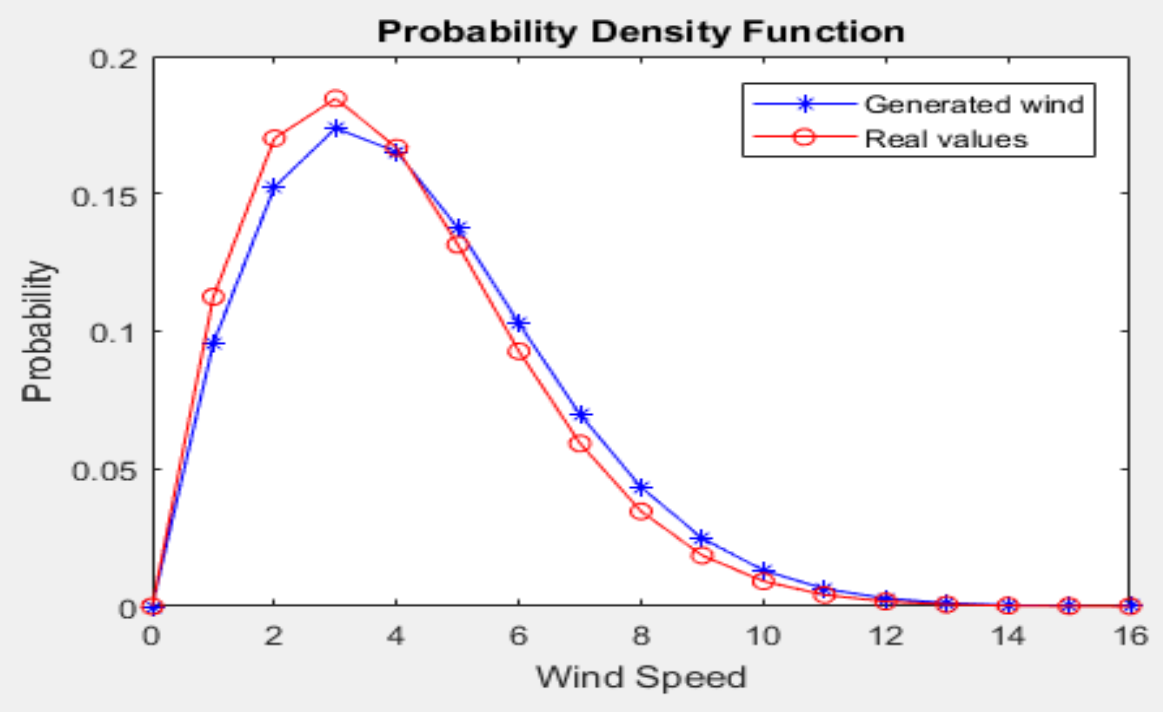

Fig. 1. Generated and historical wind speed probability

Figure 1 illustrates the compression of generated wind speed probability and historical measured wind speed probability. From this figure, it can be observed that the MCP is suitable for generating wind speed.

\subsubsection{WTG output power model}

The randomly generated wind speed is used to obtain the power generated by the WTG. The hourly power output is calculated as follows [15]:

$$
P_{W T}= \begin{cases}0 & v_{s} \prec v_{\text {cin }} \quad \text { or } \quad v_{s} \succ v_{\text {cout }} \\ \left(A * v_{s}^{3}+B^{*} P_{r}\right) & v_{\text {cin }} \leq v_{s} \leq v_{r} \\ P_{r} & v_{r} \leq v_{s} \leq v_{\text {cout }}\end{cases}
$$

where $\mathrm{P}_{r}$ is the nominal power of the WT; $\mathrm{v}_{\text {cout }}$ is the cut-out speed; $\mathrm{v}_{\text {cin }}$ is cut-in speed, and $\mathrm{v}_{r}$ is the nominal wind speed, respectively. Constants $\mathrm{A}$ and $\mathrm{B}$ are defined as follows:

$$
\begin{gathered}
A=\frac{P_{r}}{\left(v_{r}^{3}-v_{\text {cin }}^{3}\right)} \\
B=\frac{v_{\text {cin }}^{3}}{\left(v_{r}^{3}-v_{\text {cin }}^{3}\right)}
\end{gathered}
$$

Continuous power output during WTG operation impossible because it moves with the stochastic nature of the wind speed. The absence of WTG or its equivalent forced outage rate (EFOR) can be formulated as follows: 


$$
\begin{gathered}
\text { Capacity factor }(C F)=\frac{\text { Actual power output }}{\text { Rated power output }} \\
\text { EFOR }=p_{o}+\sum \frac{t_{l} C F}{T}
\end{gathered}
$$

where $p_{o}$ is total power outage probability, $t_{l}$ is the time of the shortened output in the interval $l, \mathrm{~T}$ is the total time of the study.

The received EFOR for WTG has been computed based on wind speed, and no mechanical being of WTG has been considered here. Besides, mechanical FOR of thus WTG must be combined with EFOR.

\subsection{Load demand model}

In assessing the reliability of a PGS, the load demand is a vital parameter of a stochastic nature and therefore makes it difficult to design a load demand model. Thus, a basic load demand data set is required to develop it. Typically, this is the minimum amount of data required to develop a chronological hourly load demand profile for a study period. In this study, we collect load demand data from RBTS, which is the percentage of annual load demand at the top of the weekly load demand rise, the percentage of weekly load demand at the maximum of the daily load demand, and the percentage at the maximum of the hourly load demand [17]. Using a percentage of the available load demand data, the annual maximum is $185 \mathrm{MW}$. the hourly load demand profile is shown in Figure 2.

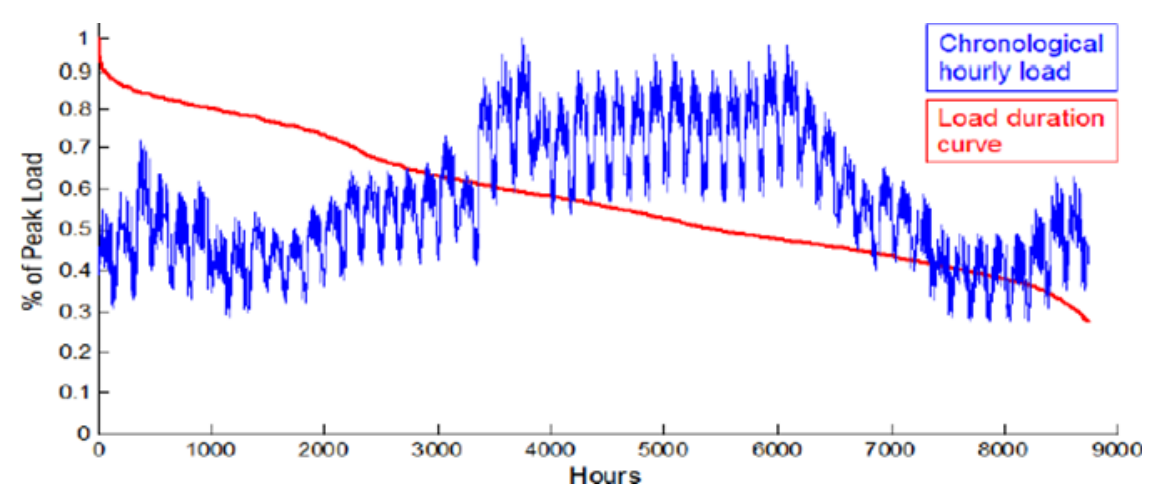

Fig. 2. Chronological hourly load and load duration curve

\section{Results and Discussion}

This section analyses the reliability of the PGS when wind power is available. The existing RBTS has been used for analysis. RBTS has a total installed capacity of $240 \mathrm{MW}$. The generation data of RBTS and other information can be found in [17]. The EFOR of WTG systems is 0.7812 , computed for simulated wind speed and FOR due to mechanical WTG failure varies from 0 to 10 percent. Besides, the conceptual model for assessing the adequacy of capacity for systems involving wind energy depicts in Figure 3. The specification of WTG is presented in Table 1. 
Table 1. The specification of WT

\begin{tabular}{|c|c|}
\hline Name & Value \\
\hline Nominal power of the WT, $\mathrm{P}_{r}$ & $2 \mathrm{MW}$ \\
\hline Cut-out speed, $\mathrm{v}_{\text {cout }}$ & $16 \mathrm{~m} / \mathrm{s}$ \\
\hline Cut-in speed, $\mathrm{v}_{\text {cin }}$ & $3 \mathrm{~m} / \mathrm{s}$ \\
\hline Nominal wind speed, $\mathrm{v}_{r}$ & $\underline{8 \mathrm{~m} / \mathrm{s}}$ \\
\hline
\end{tabular}

To the original RBTS, the first $30 \mathrm{MW}$ of WTG and then $90 \mathrm{MW}$ of WTG will be added. The COPT has been calculated for both conditions along with the RBTS from the generation data and presented in Table 2.

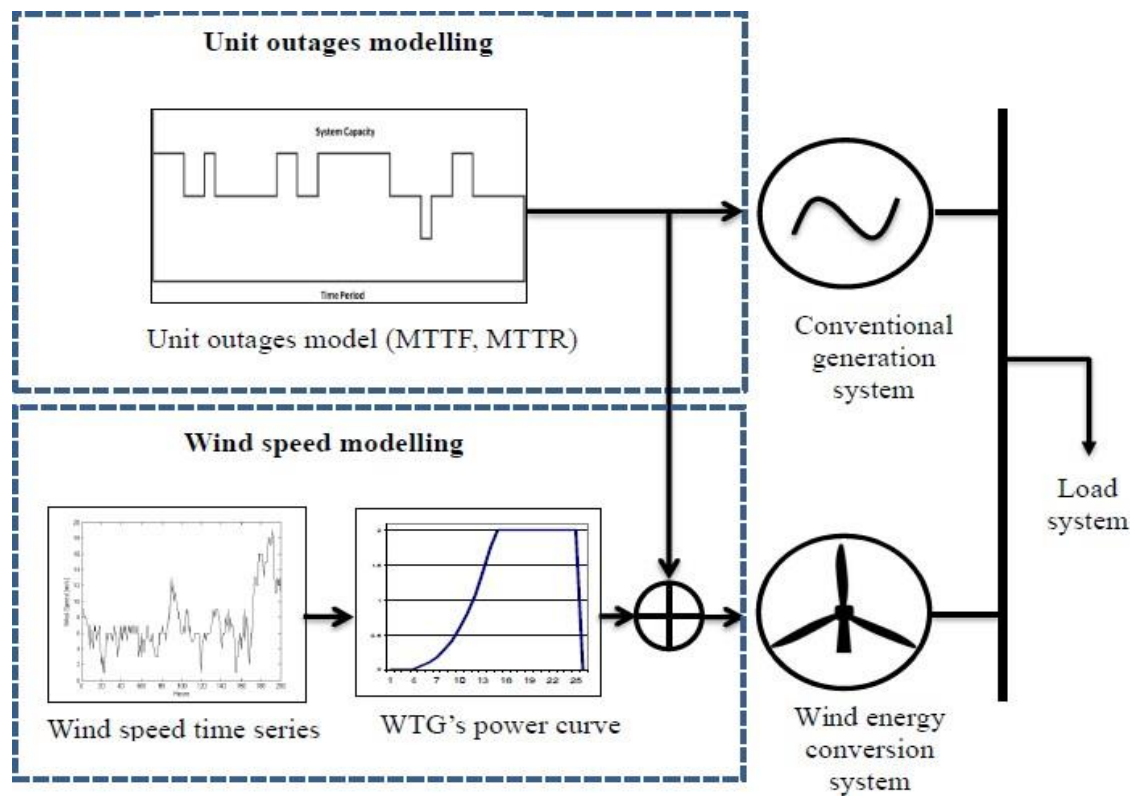

Fig. 3. The conceptual model for assessing the adequacy of capacity for systems involving wind energy

The COPT of the different states of the system is assembled separately with the load demand model, and the loss of load probability (LOLP) and expected energy not supplied (EENS) are determined for different values of the maximum load demand for the three conditions.

Figures 4 and 5 illustrate the LOLP and EENS of the original RBTS at rising the maximum load from $185 \mathrm{MW}$ to $195 \mathrm{MW}$. From these figures, it can observe how the reliability indicators of the system change when maximum load changes. 
Table 2. Calculated COPT of the generation unit

\begin{tabular}{|c|c|c|c|c|c|}
\hline \multicolumn{6}{|c|}{ COPT } \\
\hline \multicolumn{2}{|c|}{ Original RBTS } & \multicolumn{2}{|c|}{$\begin{array}{c}\text { Original RBTS with } 30 \\
\text { MW WTG }\end{array}$} & \multicolumn{2}{|c|}{$\begin{array}{c}\text { Original RBTS with } 90 \mathrm{MW} \\
\text { WTG }\end{array}$} \\
\hline $\begin{array}{l}\text { Capacity } \\
\text { (MW) }\end{array}$ & Probability & $\begin{array}{l}\text { Capacity } \\
\text { (MW) }\end{array}$ & Probability & $\begin{array}{l}\text { Capacity } \\
\text { (MW) }\end{array}$ & Probability \\
\hline 240 & $8.21 \mathrm{E}-01$ & 270 & $5.68 \mathrm{E}-02$ & 330 & $5.04 \mathrm{E}-02$ \\
\hline 235 & $1.69 \mathrm{E}-02$ & 265 & $1.63 \mathrm{E}-02$ & 325 & $1.04 \mathrm{E}-03$ \\
\hline 230 & $2.12 \mathrm{E}-02$ & 260 & $3.76 \mathrm{E}-02$ & 320 & $1.30 \mathrm{E}-03$ \\
\hline 225 & $4.33 \mathrm{E}-04$ & 255 & $4.60 \mathrm{E}-02$ & 315 & $1.19 \mathrm{E}-02$ \\
\hline 220 & $5.79 \mathrm{E}-02$ & 250 & $8.17 \mathrm{E}-02$ & 310 & $3.80 \mathrm{E}-03$ \\
\hline 215 & $1.19 \mathrm{E}-03$ & 245 & $1.42 \mathrm{E}-01$ & 305 & $3.78 \mathrm{E}-04$ \\
\hline 210 & $1.49 \mathrm{E}-03$ & 240 & $4.62 \mathrm{E}-01$ & 300 & $3.83 \mathrm{E}-02$ \\
\hline 205 & $3.06 \mathrm{E}-05$ & 235 & $1.62 \mathrm{E}-02$ & 295 & $1.62 \mathrm{E}-03$ \\
\hline 200 & $6.91 \mathrm{E}-02$ & 230 & $2.20 \mathrm{E}-02$ & 290 & $5.25 \mathrm{E}-03$ \\
\hline 195 & $1.42 \mathrm{E}-03$ & 225 & $1.16 \mathrm{E}-02$ & 285 & $4.62 \mathrm{E}-02$ \\
\hline 190 & $1.78 \mathrm{E}-03$ & 220 & $3.56 \mathrm{E}-02$ & 280 & $3.75 \mathrm{E}-03$ \\
\hline 185 & $3.65 \mathrm{E}-05$ & 215 & $4.79 \mathrm{E}-03$ & 275 & $2.24 \mathrm{E}-03$ \\
\hline 180 & $4.79 \mathrm{E}-03$ & 210 & $7.70 \mathrm{E}-03$ & 270 & $8.09 \mathrm{E}-02$ \\
\hline 175 & $9.83 \mathrm{E}-05$ & 205 & $1.20 \mathrm{E}-02$ & 265 & 4.94E-03 \\
\hline 170 & $1.23 \mathrm{E}-04$ & 200 & $3.89 \mathrm{E}-02$ & 260 & $5.37 \mathrm{E}-03$ \\
\hline 165 & $2.53 \mathrm{E}-06$ & 195 & $1.36 \mathrm{E}-03$ & 255 & $1.45 \mathrm{E}-01$ \\
\hline 160 & $1.95 \mathrm{E}-03$ & 190 & $1.58 \mathrm{E}-03$ & 250 & $8.86 \mathrm{E}-03$ \\
\hline 155 & $4.02 \mathrm{E}-05$ & 185 & $8.82 \mathrm{E}-04$ & 245 & $7.73 \mathrm{E}-03$ \\
\hline 150 & $5.04 \mathrm{E}-05$ & 180 & $2.76 \mathrm{E}-03$ & 240 & $4.50 \mathrm{E}-01$ \\
\hline 145 & $1.03 \mathrm{E}-06$ & 175 & $1.85 \mathrm{E}-04$ & 235 & $1.96 \mathrm{E}-02$ \\
\hline 140 & $1.30 \mathrm{E}-04$ & 170 & $2.63 \mathrm{E}-04$ & 230 & $1.86 \mathrm{E}-02$ \\
\hline 135 & $2.68 \mathrm{E}-06$ & 165 & $3.40 \mathrm{E}-04$ & 225 & $9.09 \mathrm{E}-04$ \\
\hline 130 & $3.36 \mathrm{E}-06$ & 160 & $1.10 \mathrm{E}-03$ & 220 & $3.20 \mathrm{E}-02$ \\
\hline 125 & $6.88 \mathrm{E}-08$ & 155 & $3.81 \mathrm{E}-05$ & 215 & $1.28 \mathrm{E}-02$ \\
\hline 120 & $1.97 \mathrm{E}-05$ & 150 & $4.17 \mathrm{E}-05$ & 210 & $1.54 \mathrm{E}-03$ \\
\hline 115 & $4.04 \mathrm{E}-07$ & 145 & $2.34 \mathrm{E}-05$ & 205 & $4.50 \mathrm{E}-04$ \\
\hline 110 & $5.07 \mathrm{E}-07$ & 140 & $7.37 \mathrm{E}-05$ & 200 & $3.79 \mathrm{E}-02$ \\
\hline 105 & $1.04 \mathrm{E}-08$ & 135 & $3.16 \mathrm{E}-06$ & 195 & $1.62 \mathrm{E}-03$ \\
\hline 100 & $1.18 \mathrm{E}-06$ & 130 & $3.81 \mathrm{E}-06$ & 190 & 1.19E-03 \\
\hline 95 & $2.43 \mathrm{E}-08$ & 125 & $3.44 \mathrm{E}-06$ & 185 & $5.30 \mathrm{E}-05$ \\
\hline 90 & $3.05 \mathrm{E}-08$ & 120 & $1.10 \mathrm{E}-05$ & 180 & $2.63 \mathrm{E}-03$ \\
\hline 85 & $6.24 \mathrm{E}-10$ & 115 & $3.76 \mathrm{E}-07$ & 175 & $3.98 \mathrm{E}-04$ \\
\hline
\end{tabular}




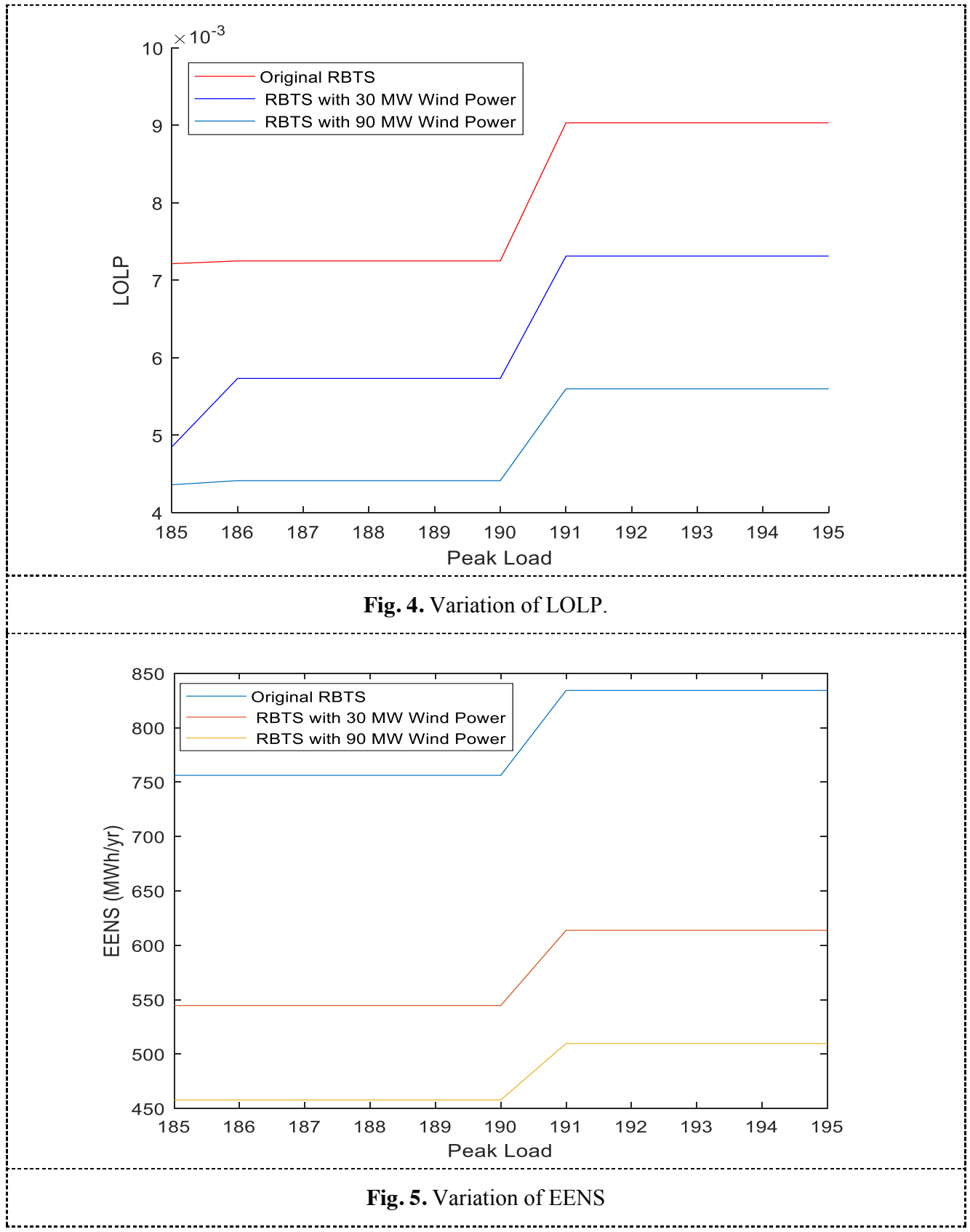

It can be seen from Figure 4, the existing RBTS with a capacity of $185 \mathrm{MW}$, the LOLP system is equal to 7.21E-03, and when WTG of $30 \mathrm{MW}$ and $90 \mathrm{MW}$ is added, it is reduced to $4.85 \mathrm{E}-03$ and $4.36 \mathrm{E}-03$, respectively. It can be seen from Figure 5 , the existing RBTS with a capacity of $185 \mathrm{MW}$, the EENS system is equal to $756.165 \mathrm{MWh} / \mathrm{yr}$, and when WTG of $30 \mathrm{MW}$ and $90 \mathrm{MW}$ is added, it is reduced to $544.5365 \mathrm{MWh} / \mathrm{yr}$ and 457.7726 MWh/yr, respectively.

Figure 6 illustrates the Loss of Load Expectation (LOLE) variation of the WTG with FOR. It can observe from the figure, the FOR of WTG does not cause many 
inconveniences on the system. It follows that the mechanical failure of the WTG can be neglected in a large WTG system.

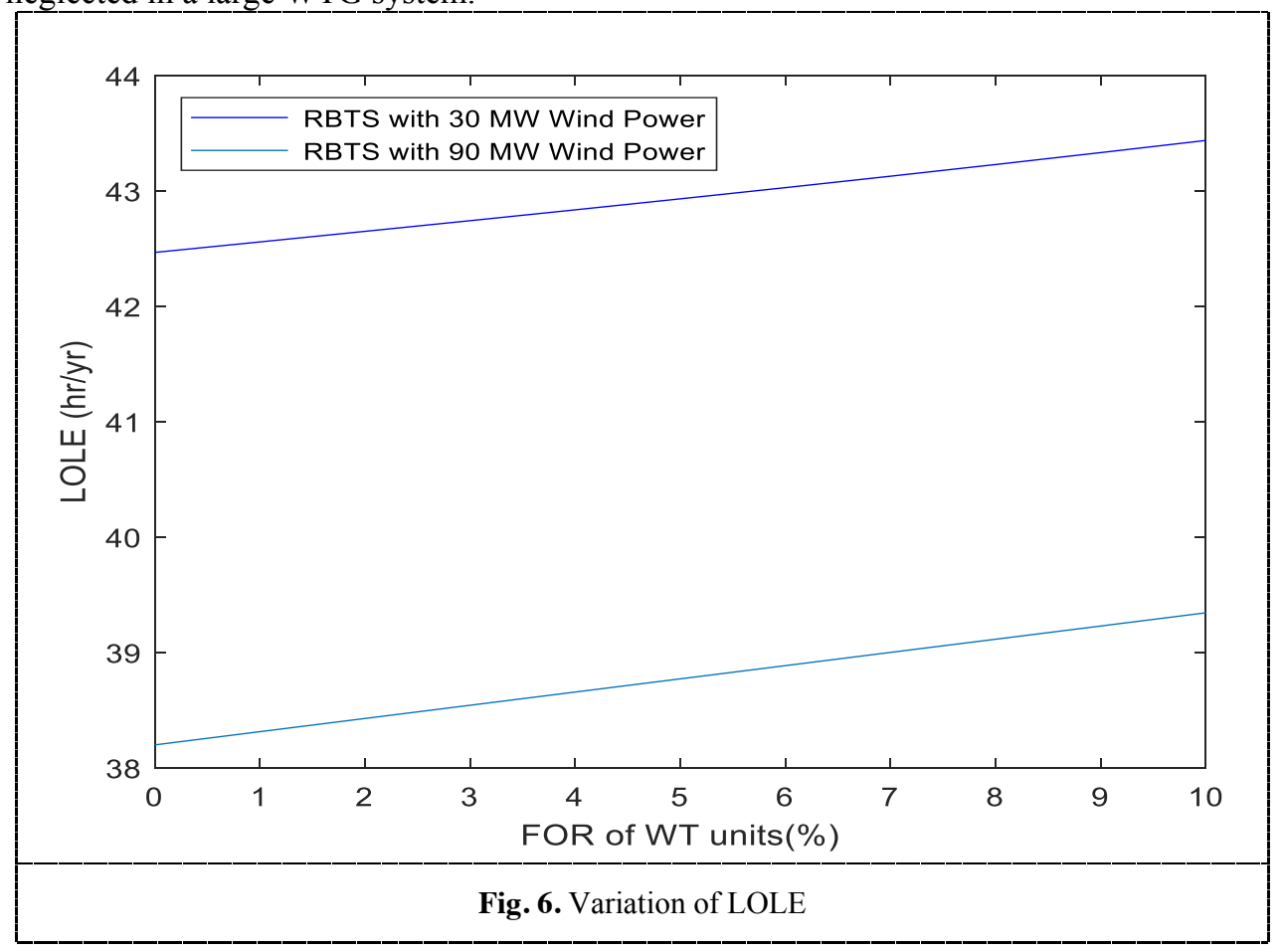

\section{Conclusion}

In recent years, the development of techniques for assessing the reliability of WTG systems is becoming increasingly important. Thus, WTG is growing rapidly, and it remains a major challenge to incorporate it with the existing power grid. In this paper, the reliability indicators such as LOLP, EENS, and LOLE items, which are commonly used, have been successfully calculated. Various system cases were considered during the analysis. As a result, the increase in WTG has seen an improvement in the reliability of the system. Besides, the mechanical failure of the WTG does not much affect the reliability of the PGS. Hence, it can be concluded that the proposed model is good enough for the planner to calculate the system reliability indicators by integrating WTG.

\section{References}

1. Khasanov M, Kamel S, Tostado-Véliz M and Jurado F. IEEE International Conference on Environment and Electrical Engineering 1-5, (2020)

2. Elkadeem M R, Elaziz M A, Ullah Z, Wang S and Sharshir S W. Optimal Planning of Renewable Energy-Integrated Distribution System Considering Uncertainties, (2019)

3. Khasanov M, Kamel S, Xie K, Zhou P and Li B. Allocation of Distributed Generation in Radial Distribution Networks Using an Efficient Hybrid Optimization Algorithm 2019 IEEE Innovative Smart Grid Technologies - Asia (ISGT Asia) pp 1300-1305, (2019)

4. Khasanov M, Kamel S and Abdel-Mawgoud H. 21st International Middle East Power Systems Conference (MEPCON) p p . 354-359, (2019) 
5. Keane A, Milligan M, Dent C J, Hasche B, D’Annunzio C, Dragoon K, Holttinen H, Samaan N, Soder L and O’Malley M. IEEE Transactions on Power Systems 26, pp. 564-572, (2011)

6. Billinton R and Gao Y 2008 IEEE Transactions on Energy Conversion 23, 163-170, (2008)

7. Karki R, Hu P and Billinton R. IEEE Transactions on Energy Conversion, 21, pp. 533540 (2006)

8. Ghaedi A, Abbaspour A, Fotuhi-Firuzabad $M$ and Moeini-Aghtaie M. IEEE Transactions on Sustainable Energy 5, pp. 55-63, (2014)

9. Leite A P, Borges C L T and Falcão D M 2006 IEEE Trans. Power Syst 21, p p. 1493-1501, (2006)

10. Wangdee W and Billinton R. IEEE Transactions on Energy Conversion 21, pp.734741, (2006)

11. Billinton R, Gao Y and Karki R. IEEE Transactions on Power Systems 24, pp.13751382, (2009)

12. Kim H and Singh C IEEE Grenoble Conf. PowerTech,(2013)

13. Qin Z, Li W and Xiong X. Appl. Energy 110 285-294, (2013)

14. Abdullah M.A, Muttaqi K.M, Agalgaonkar A.P. and Sutanto D. IEEE Transactions on Sustainable Energy 5, p. 854, (2014)

15. Kayal P., and Chanda C.K. Optimal mix of solar and wind distributed generations considering performance improvement of electrical distribution network, (2015)

16. Billinton R and Gan L. IEEE Transactions on Power Systems 6, pp.1571-1577, (1991) URL 10.1109/59.117004;https://dx.doi.org/10.1109/59.117004

17. Billinton R., Kumar S., Chowdhury N., Chu K., Debnath K., Goel L., Khan E., Kos P., Nourbakhsh G, and Oteng-Adjei J. IEEE Transactions on Power Systems 4, pp.12381244 (1989) 